\title{
Technical note: Using distributed temperature sensing for Bowen ratio evaporation measurements
}

\author{
Bart Schilperoort $^{1}$, Miriam Coenders-Gerrits ${ }^{1}$, Willem Luxemburg ${ }^{1}$, César Jiménez Rodríguez ${ }^{1,3}$, \\ César Cisneros Vaca ${ }^{2}$, and Hubert Savenije ${ }^{1}$ \\ ${ }^{1}$ Delft University of Technology, Water Resources Section, Stevinweg 1, 2628 CN Delft, the Netherlands \\ ${ }^{2}$ University of Twente, Faculty of Geo-Information Science and Earth Observation (ITC), \\ Hengelosestraat 99, 7514 AE, Enschede, the Netherlands \\ ${ }^{3}$ Tecnológico de Costa Rica, Escuela de Ingeniería Forestal. 159-7050, Cartago, Costa Rica
}

Correspondence: Bart Schilperoort (b.schilperoort@tudelft.nl)

Received: 21 July 2017 - Discussion started: 4 August 2017

Revised: 27 November 2017 - Accepted: 20 December 2017 - Published: 30 January 2018

\begin{abstract}
Rapid improvements in the precision and spatial resolution of distributed temperature sensing (DTS) technology now allow its use in hydrological and atmospheric sciences. Introduced by Euser et al. (2014) is the use of DTS for measuring the Bowen ratio (BR-DTS), to estimate the sensible and latent heat flux. The Bowen ratio is derived from DTS-measured vertical profiles of the air temperature and wet-bulb temperature. However, in previous research the measured temperatures were not validated, and the cables were not shielded from solar radiation. Additionally, the BRDTS method has not been tested above a forest before, where temperature gradients are small and energy storage in the air column becomes important.

In this paper the accuracy of the wet-bulb and air temperature measurements of the DTS are verified, and the resulting Bowen ratio and heat fluxes are compared to eddy covariance data. The performance of BR-DTS was tested on a $46 \mathrm{~m}$ high tower in a mixed forest in the centre of the Netherlands in August 2016. The average tree height is 26 to $30 \mathrm{~m}$, and the temperatures are measured below, in, and above the canopy. Using the vertical temperature profiles the storage of latent and sensible heat in the air column was calculated.

We found a significant effect of solar radiation on the temperature measurements, leading to a deviation of up to $3 \mathrm{~K}$. By installing screens, the error caused by sunlight is reduced to under $1 \mathrm{~K}$. Wind speed seems to have a minimal effect on the measured wet-bulb temperature, both below and above the canopy. After a simple quality control, the Bowen ratio measured by DTS correlates well with eddy covariance
\end{abstract}

(EC) estimates $\left(r^{2}=0.59\right)$. The average energy balance closure between BR-DTS and EC is good, with a mean underestimation of $3.4 \mathrm{~W} \mathrm{~m}^{-2}$ by the BR-DTS method. However, during daytime the BR-DTS method overestimates the available energy, and during night-time the BR-DTS method estimates the available energy to be more negative. This difference could be related to the biomass heat storage, which is neglected in this study.

The BR-DTS method overestimates the latent heat flux on average by $18.7 \mathrm{~W} \mathrm{~m}^{-2}$, with RMSE $=90 \mathrm{~W} \mathrm{~m}^{-2}$. The sensible heat flux is underestimated on average by $10.6 \mathrm{~W} \mathrm{~m}^{-2}$, with RMSE $=76 \mathrm{~W} \mathrm{~m}^{-2}$. Estimates of the BR-DTS can be improved once the uncertainties in the energy balance are reduced. However, applying, for example, Monin-Obukhov similarity theory could provide independent estimates for the sensible heat flux. This would make the determination of the highly uncertain and difficult to determine net available energy redundant.

\section{Introduction}

In recent years distributed temperature sensing (DTS) technology has quickly improved (Bao and Chen, 2012). The precision and spatial resolution now allow its widespread use in hydrological and atmospheric sciences (Selker et al., 2006; Thomas et al., 2012), from measuring groundwater flow (Blume et al., 2013) and seepage into streams (Westhoff et al., 2007) to soil moisture (Steele-Dunne et al., 2010), 
soil heat flux (Bense et al., 2016), and wind speed (Sayde et al., 2015). First introduced by Euser et al. (2014), DTS can also be used for measuring the Bowen ratio, to estimate the evaporation flux. A dry and wet stretch of the same fibre optic cable are installed vertically to obtain the so-called dryand wet-bulb temperature gradient, respectively. This method mitigates some problems of the conventional Bowen ratio, since usually at least two different sensors are used to measure the temperature and vapour pressure gradients, of which each has its own independent error (Angus and Watts, 1984; Fuchs and Tanner, 1970). The DTS-based Bowen ratio does not suffer from this drawback, by having a large amount of data points over the height (up to 8 per metre) with only a single sensor. It also has a resolution of $0.06 \mathrm{~K}$ for $1 \mathrm{~min}$ averages (Silixa machine calibration), and will be more accurate when measuring over a longer time period, allowing for very small temperature gradients to be measured.

In addition to estimating the latent and sensible heat flux, the measurements can also be used to get a better understanding of the processes taking place in complex ecosystems, such as forests. A vertical temperature and humidity profile is available in high resolution and precision, both above, inside, and under the canopy. DTS can also estimate different components of the energy balance, such as the heat storage in the air column, and the soil heat flux (Jansen et al., 2011). Finally, it can be used to increase our understanding of the energy exchange between the canopy and undergrowth layers by looking at the air temperature gradient under the canopy.

This paper elaborates on the method of Euser et al. (2014), by considering more energy balance components like the latent and sensible heat storage in the air column, including a data-quality system, and using the potential air temperature. The performance of the method is tested in a mixed forest in the Netherlands by looking at the accuracy of the DTSmeasured air temperature and wet-bulb temperature, compared to reference temperature and humidity sensors. It appears that solar radiation can have a significant influence on the cable temperature, which can be mitigated by providing artificial shadow. Lastly, the fluxes resulting from the method are compared to an eddy covariance (EC) system, and the sources of differences between the methods are shown.

\section{Materials and methods}

\subsection{Theory}

The Bowen ratio energy balance method (BREB) combines the energy balance with the Bowen ratio (Oliphant et al., 2004). The energy balance can be described by

$R_{\mathrm{N}}+A=\rho \lambda E+H+G_{\mathrm{S}}+\frac{\mathrm{d} Q}{\mathrm{~d} t}$,

where $R_{\mathrm{N}}$ is the net radiation $\left(\mathrm{W} \mathrm{m}^{-2}\right), \rho \lambda E$ the latent heat flux $\left(\mathrm{W} \mathrm{m}^{-2}\right), H$ the sensible heat flux $\left(\mathrm{W} \mathrm{m}^{-2}\right), G_{\mathrm{S}}$ the soil heat flux $\left(\mathrm{W} \mathrm{m}^{-2}\right)$, and $\frac{\mathrm{d} Q}{\mathrm{~d} t}$ is the change of energy storage in the system $\left(\mathrm{W} \mathrm{m}^{-2}\right)$. A represents a net advection of energy into the system $\left(\mathrm{W} \mathrm{m}^{-2}\right)$, but is assumed to be 0 . The energy flux associated with photosynthesis $\left(G_{\mathrm{P}}\right)$ was not measured, and is therefore not included in the equation. The Bowen ratio $(\beta)$ is the ratio of the sensible heat flux to the latent heat flux and can be approximated using the air temperature gradient and the vapour pressure difference over the height (Bowen, 1926)

$$
\beta=\frac{H}{\rho \lambda E} \approx \gamma \frac{\Delta T_{\mathrm{a}}}{\Delta e_{\mathrm{a}}}
$$

where $\gamma$ is the psychrometric constant $\left(\mathrm{kPaK}^{-1}\right.$ ) (see Eq. 10), $\Delta T_{\mathrm{a}}$ the difference in air temperature between two heights $(\mathrm{K})$ and $\Delta e_{\mathrm{a}}$ the difference in actual vapour pressure between the two heights $(\mathrm{kPa})$. However, when gradients are very small, the adiabatic lapse rate cannot be neglected (Barr et al., 1994). Therefore the potential temperature should be used instead:

$\beta=\frac{H}{\rho \lambda E}=\frac{c_{p}}{\lambda} \frac{\partial \Theta / \partial z}{\partial q / \partial z}=\gamma \frac{\partial \Theta / \partial z}{\partial e_{\mathrm{a}} / \partial z}$,

where $c_{p}$ is the specific heat of air $\left(\mathrm{MJ} \mathrm{kg}^{-1}\right)$ (see Eq. 6), $\lambda$ the latent heat of vaporization $\left(2.45 \mathrm{MJ} \mathrm{kg}^{-1} \mathrm{~K}^{-1}\right), \Theta$ the potential temperature $(\mathrm{K}), q$ the specific humidity $\left(\mathrm{kg} \mathrm{kg}^{-1}\right)$ (see Eq. 7) and $z$ the height above the ground (m). The potential temperature gradient can be approximated by the righthand side of Eq. (4), as the ratio $\frac{\Theta}{T_{\mathrm{a}}}$ is nearly 1 (Pal Arya, 1988):

$\frac{\partial \Theta}{\partial z}=\frac{\Theta}{T_{\mathrm{a}}}\left(\frac{\partial T_{\mathrm{a}}}{\partial z}+\Gamma\right) \approx \frac{\partial T_{\mathrm{a}}}{\partial z}+\Gamma$,

where $T_{\mathrm{a}}$ is the air temperature $(\mathrm{K})$, and $\Gamma$ is the adiabatic lapse rate (typically around $0.01 \mathrm{~K} \mathrm{~m}^{-1}$ ). The numerical implementations of Eqs. (3) and (4) are explained in Sect. 3.2. Under dry and unsaturated conditions the lapse rate is equal to (Pal Arya, 1988)

$\Gamma=\frac{g}{c_{p}}$,

where $g$ is the gravitational acceleration $\left(9.81 \mathrm{~m} \mathrm{~s}^{-2}\right)$. The specific heat capacity of air is determined by (Stull, 2015)

$c_{p}=1.004+1.84 q$

and the specific humidity by (Pal Arya, 1988)

$q=\varepsilon \frac{e_{\mathrm{a}}}{P}$,

where $\varepsilon$ is the ratio of molecular mass of water vapour to dry air (0.622), and $P$ the atmospheric pressure (kPa). The actual vapour pressure is determined by (Allen et al., 1998)

$e_{\mathrm{a}}\left(T_{\mathrm{a}}\right)=e_{\mathrm{s}}\left(T_{\mathrm{w}}\right)-\gamma\left(T_{\mathrm{a}}-T_{\mathrm{w}}\right)$, 

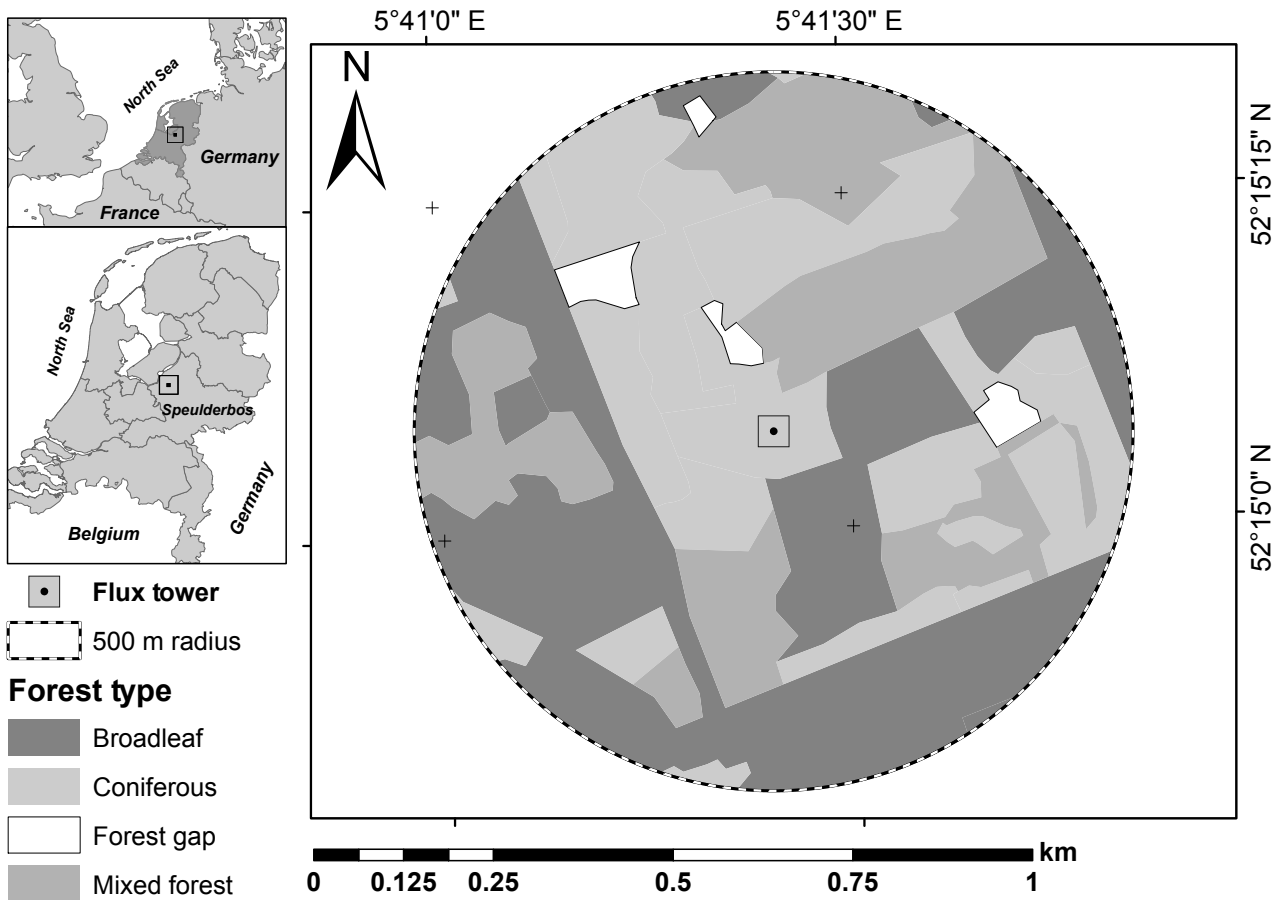

Figure 1. Forest type distribution within $500 \mathrm{~m}$ of the tower site at Speulderbos Forest, the Netherlands.

where $T_{\mathrm{w}}$ is the wet-bulb temperature $(\mathrm{K})$, and $e_{\mathrm{S}}$ the saturation vapour pressure $(\mathrm{kPa})$ given by (Koutsoyiannis, 2012)

$e_{\mathrm{S}}\left(T_{\mathrm{w}}\right)=0.61 \cdot \exp \left(\frac{19.9 \cdot T_{\mathrm{w}}}{273+T_{\mathrm{w}}}\right)$

The psychrometer constant is related to the air pressure and ventilation of the psychrometer (Harrison and Wood, 2012; Allen et al., 1998). If sufficiently ventilated, the psychrometric constant is defined by (Allen et al., 1998)

$\gamma=\frac{c_{p} P}{\varepsilon \lambda}=0.665 \times 10^{-3} \cdot P$.

As the air pressure also varies over height, the measurements have to be corrected for elevation using the following approximation (Stull, 2015, p. 8):

$P(z)=P_{0} \cdot \exp (-z / 7290)$

with $P_{0}$ being the pressure at sea level $(\mathrm{kPa})$. By combining the Bowen ratio (Eq. 3) with the energy balance (Eq. 1), the latent heat flux and sensible heat flux can be determined:

$H=\frac{R_{\mathrm{N}}-G_{\mathrm{S}}-\frac{\mathrm{d} Q}{\mathrm{~d} t}}{1+\frac{1}{\beta}}$,

$\rho \lambda E=\frac{R_{\mathrm{N}}-G_{\mathrm{S}}-\frac{\mathrm{d} Q}{\mathrm{~d} t}}{1+\beta}$

The storage component in the energy balance has multiple parts, ranging from the storage of heat in the soil, to the stor- age of heat in the form of water vapour in the air column:

$\frac{\mathrm{d} Q}{\mathrm{~d} t}=\frac{\mathrm{d} Q_{H}}{\mathrm{~d} t}+\frac{\mathrm{d} Q_{E}}{\mathrm{~d} t}$

The changes in storage of heat and water vapour in the air column below the height at which the energy fluxes $\left(R_{\mathrm{N}}\right.$, $H$ and $\rho \lambda E)$ are measured are represented by $\frac{\mathrm{d} Q_{H}}{\mathrm{~d} t}$ and $\frac{\mathrm{d} Q_{E}}{\mathrm{~d} t}$ respectively $\left(\mathrm{W} \mathrm{m}^{-2}\right)$. The change in biomass heat storage $\left(\frac{\mathrm{d} Q_{B}}{\mathrm{~d} t}\right)$ was not measured, and is therefore not included in this equation. $\frac{\mathrm{d} Q_{H}}{\mathrm{~d} t}$ and $\frac{\mathrm{d} Q_{E}}{\mathrm{~d} t}$ are defined as (Barr et al., 1994)

$$
\begin{aligned}
\frac{\mathrm{d} Q_{H}}{\mathrm{~d} t} & =\int_{0}^{z} \rho_{\mathrm{a}} c_{p} \frac{\mathrm{d} T_{\mathrm{a}}}{\mathrm{d} t} \mathrm{~d} z, \\
\frac{\mathrm{d} Q_{E}}{\mathrm{~d} t} & =\int_{0}^{z} \rho_{\mathrm{a}} \lambda \frac{\mathrm{d} q}{\mathrm{~d} t} \mathrm{~d} z .
\end{aligned}
$$

\section{Study site}

The measurements were carried out at the Speulderbos mixed forest $\left(52^{\circ} 15^{\prime} 4^{\prime \prime} \mathrm{N}, 5^{\circ} 41^{\prime} 24^{\prime \prime} \mathrm{E}\right)$, on a tower located within a patch of Douglas fir trees (Pseudotsuga menziesii (Mirb.) Franco) of 2.5 ha in Garderen, the Netherlands (Fig. 1). The surrounding area is characterized by the presence of broadleaved and coniferous tree species, distributed in blocks around the tower site (Bosveld and Bouten, 2001). Within a 


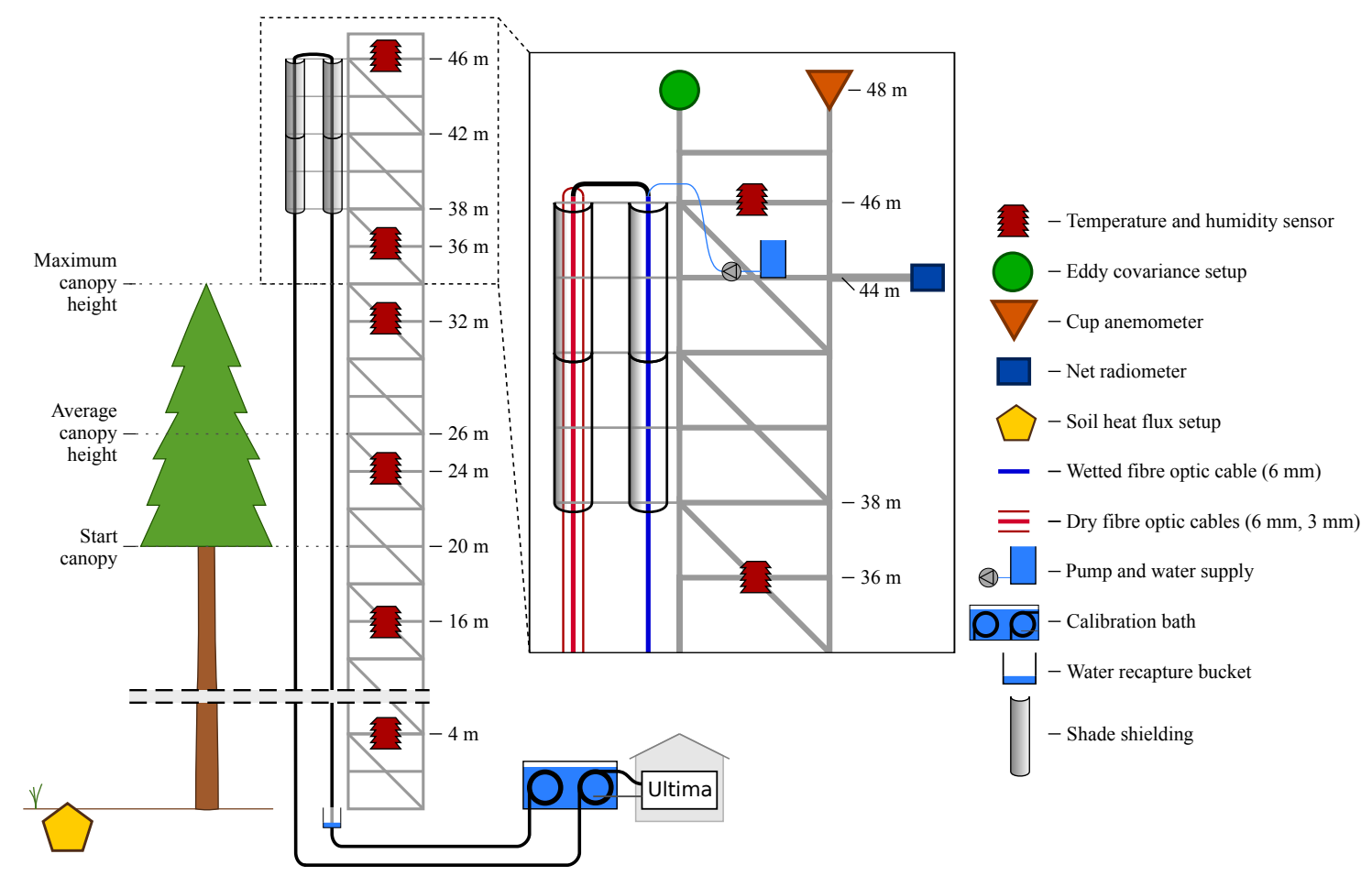

Figure 2. Schematic overview of the measurement setup at the tower.

$500 \mathrm{~m}$ radius it is possible to find native tree species such as beech (Fagus sylvatica L.), pedunculate oak (Quercus robur L.) and Scots pine (Pinus sylvestris L.), as well as the introduced species hemlock (Tsuga heterophylla (Rafinesque) Sargent) and Japanese larch (Larix kaempferi (Lambert) Carriére) (Erisman et al., 1998; Raj et al., 2014; Su et al., 2009; Bosveld and Bouten, 2001; Tietema et al., 2002; Van Wijk et al., 2000; Weligepolage et al., 2013). Canopy heights differ between cover types depending on species and growing stage. Some coniferous canopies like the Douglas fir have a canopy height between 26 and $30 \mathrm{~m}$, while the broadleaved stands can reach up to $30 \mathrm{~m}$ height for old-growth beech trees (Weligepolage et al., 2012; Wilkes et al., 2017), or heights under $10 \mathrm{~m}$ for smaller pedunculate oak trees.

The study site has an oceanic climate $(\mathrm{Cfb})$ under the Köpen classification system, with a yearly average temperature of $9.8^{\circ} \mathrm{C}$ and an average precipitation of $910 \mathrm{~mm} \mathrm{yr}^{-1}$ (Sluijter, 2011). The topography is slightly undulating with smooth height differences (Raj et al., 2014), a well-drained soil, and a groundwater table below $40 \mathrm{~m}$ depth (Tiktak and Bouten, 1994). The soil texture ranges from fine sand to sandy loam (Weligepolage et al., 2012; Tietema et al., 2002; Van Wijk et al., 2000).

\subsection{Setup}

The temperature of fibre optic cables is measured using the DTS technique (Selker et al., 2006). In the setup, two cables with different diameters were used. The first cable has a di- ameter of $6 \mathrm{~mm}$ and has both a dry and a wetted stretch. To wet the cable it was wrapped in cloth, and water was supplied to it continuously. A second cable with a diameter of $3 \mathrm{~mm}$ was used to study the effects of solar radiation, as a thinner cable will warm up less (De Jong et al., 2015). However, this method added additional uncertainties due to the required extrapolation and the $3 \mathrm{~mm}$ cable was not used in this study. (While correlation with reference sensors improved, the uncertainty of extrapolation caused extra noise in the Bowen ratio calculations). Both cables were connected to the same DTS machine (in single-ended mode) and calibrated in a calibration bath (see Fig. 2)

The DTS machine used was the Silixa Ultima (Silixa Ltd, 2017), which has a sampling resolution of $12.5 \mathrm{~cm}$, measurement resolution of $35 \mathrm{~cm}$, and a measurement standard deviation of $0.06 \mathrm{~K}$ at a $1 \mathrm{~min}$ time resolution.

The fibre optic cable with a diameter of $6 \mathrm{~mm}$ was secured at the top of the tower, with the dry stretch hanging $1.2 \mathrm{~m}$ away from the tower, and the wet stretch $0.25 \mathrm{~m}$ away. The cable with a diameter of $3 \mathrm{~mm}$ was secured next to the dry $6 \mathrm{~mm}$ cable. The response times of the cables are of the order of 2-3 min for the $6 \mathrm{~mm}$ cable, and 20 to $40 \mathrm{~s}$ for the $3 \mathrm{~mm}$ cable. The cables were secured at multiple locations distributed over the height (in and above the canopy; see Fig. 2), using loops (with a diameter of $5 \mathrm{~cm}$ ) to prevent direct contact with the support structure. For both cables a stretch of $10 \mathrm{~m}$ at both the start and end was placed in a calibration bath, an enclosed styrofoam box filled with water, along with two 
Pt100 temperature probes that were connected to the DTS machine. An air bubbler was installed in the styrofoam box to ensure a homogeneous temperature distribution. The cables were shielded from direct solar radiation using screen gauze secured onto PVC rings; see Fig. 3. Only the southern $180^{\circ}$ of the cables was shielded, to allow for sufficient ventilation. The screen gauze had holes $1.5 \mathrm{~mm}$ wide, and the mesh material had a diameter of $0.3 \mathrm{~mm}$. Two layers of the gauze were used. Each segment of shield was $2 \mathrm{~m}$ long, and was secured to the tower with a horizontal beam. Due to the angle of the incident sunlight the gauze was able to block most direct sunlight, except during the early morning. To supply the wet cable with water, a reservoir was installed near the top of the tower, along with a pump. The pump speed was set to $1500 \mathrm{~mL} \mathrm{~h}^{-1}$ during sunny days without rainfall, and to $800 \mathrm{~mL} \mathrm{~h}^{-1}$ on other days, which was enough to keep the cable wet over the entire height, while keeping the influence of relatively warm water at the top of the cable at a minimum. As water supplied at the top has a higher temperature than the wet-bulb temperature, the top $2 \mathrm{~m}$ of wet cable data was excluded from the data analysis to allow the slowly flowing water to reach the wet-bulb temperature.

A net radiometer (Kipp \& Zonen CNR4) was located on the top of the tower $(48 \mathrm{~m})$, measuring both incoming and outgoing short- and longwave radiation. One-minute averages were logged. On the tower six humidity and temperature sensors were located over the height, at 4, 16, 24, 32, 36 and $46 \mathrm{~m}$ a.g.l. (above ground level). The lower four were Rotronic HC2-S3C03 sensors (with active ventilation), and the top two were Campbell CS216 sensors with passive ventilation. The sensors were inter-calibrated to the sensor at $24 \mathrm{~m}$. The temperature and humidity was logged at $1 \mathrm{~min}$ averages.

At the top of the tower an EC system was installed to measure the sensible and latent heat fluxes. It consisted of a Campbell CSAT3 sonic anemometer and a LI-COR Biosciences LI7500 gas analyser connected to a CR5000 Campbell data logger, to which the data were logged at $20 \mathrm{~Hz}$.

Two cup anemometers (Onset S-WSB-M003) were used to measure the wind speed, one at the top of the tower $(48 \mathrm{~m})$, and one below the canopy $(4 \mathrm{~m})$. The data from the lower anemometer lacks the resolution to properly measure the low wind speeds below the canopy, which are at times too low to be registered. One-minute average wind speeds, along with the maximum gust speeds, were logged.

The biomass heat storage change and the photosynthesis energy flux were not measured. The biomass heat storage change is estimated to have a maximum of $45 \mathrm{~W} \mathrm{~m}^{-2}$, and the photosynthesis energy flux is estimated to be of the order of $5 \mathrm{~W} \mathrm{~m}^{-2}$ (Barr et al., 1994; Michiles and Gielow, 2008). For the soil heat flux, the soil temperature was measured at different depths $(1,3,4,8,20,50 \mathrm{~cm})$. Soil moisture was measured using Campbell Sci. Inc. CS616 water content reflectometers. Thermal conductivity was fitted to soil heat flux

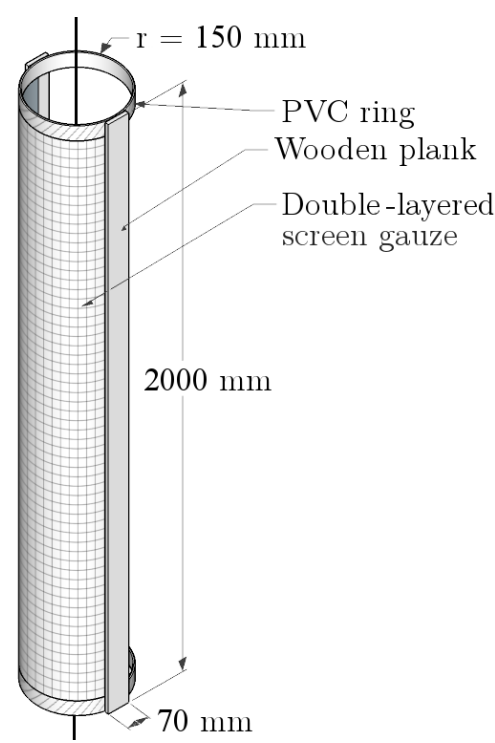

Figure 3. Schematic of one $2 \mathrm{~m}$ segment of the solar screen construction.

measurements done at $8 \mathrm{~cm}$. The soil heat flux was then determined using the harmonics method (van der Tol, 2012).

\subsection{Data processing}

The DTS machine was set to measure the cable temperature at $1 \mathrm{~min}$ averaging intervals. For the comparison with reference temperature sensors, these 1 min resolution data are used. To compare the wet-bulb temperature measured by the fibre optic cable to the reference sensors, the reference wetbulb temperature is iteratively derived from the reference air temperature and relative humidity. For the purpose of calculating the Bowen ratio, the temperature and actual vapour pressure are averaged over time for $15 \mathrm{~min}$ time periods. For DTS Bowen ratio calculations, the temperatures between 38.5 and $44 \mathrm{~m}$ are used. This area is shaded from the sun by the screen gauze, and at the top of the stretch the new water on the wet cable has reached the wet-bulb temperature.

When calculating the gradients for the Bowen ratio, the 15 min average temperature and vapour pressure are fit to the natural logarithm of the height, in the following form:

$T_{\mathrm{a}, \text { fit }}=a \cdot \ln (z)+b$.

A logarithmic shape of the profiles was assumed based on Monin-Obukhov similarity theory. A linear fit was also looked at, but it resulted in a minimal difference in the resulting fit. From the fits the temperature difference over height is then calculated:

$$
\begin{aligned}
& \frac{\partial \Theta}{\partial z} \approx \frac{\partial T_{\mathrm{a}}}{\partial z}+\Gamma(z) \approx \frac{\Delta T_{a, \mathrm{fit}}}{\Delta z}+\Gamma(z) \\
& \approx \frac{T_{\mathrm{a}, \mathrm{fit}}(z=44)-T_{\mathrm{a}, \mathrm{fit}}(z=38.5)}{44-38.5}+\Gamma(\bar{z}=41.25),
\end{aligned}
$$


$\frac{\partial e_{\mathrm{a}}}{\partial z} \approx \frac{\Delta e_{a, \mathrm{fit}}}{\Delta z}=\frac{e_{\mathrm{a}, \mathrm{fit}}(z=44)-e_{\mathrm{a}, \mathrm{fit}}(z=38.5)}{44-38.5}$,

where $\Delta T_{\mathrm{a}}$, fit is the difference in air temperature $(\mathrm{K})$ of the fitted temperature curve, between the top and bottom of the height range used for the Bowen ratio. $\Delta e_{\mathrm{a}}$, fit is the difference in vapour pressure $(\mathrm{kPa})$ of the fitted vapour pressure curve between those heights. $\Delta z$ is the difference in height (m). The coefficients of determination of the regressions of the temperature and vapour pressure, $r_{T_{\mathrm{a}}, z}$ and $r_{e_{\mathrm{a}}, z}$, can be used for determining the goodness of fit. A high (positive or negative) regression means that the logarithmic slope (of the 15 min average) is very well defined.

To calculate the air column storage terms $\frac{\mathrm{d} Q_{H}}{\mathrm{~d} t}$ and $\frac{\mathrm{d} Q_{E}}{\mathrm{~d} t}$ (Eqs. 15 and 16), the DTS-measured temperature and vapour pressure are used, except for the centre of the canopy where DTS data are not accurate due to the sunlight and lack of screens in the canopy. The temperature and specific humidity are integrated over the height from 0 to $41 \mathrm{~m}$, up to the height of the Bowen ratio measurements.

As quality control scheme for the DTS-measured Bowen ratio, two flags are used. The first flag tests the correlation coefficient of the actual vapour pressure over height, for which we chose a lower limit of 0.20 (Eq. 20). We do not consider $r_{T_{\mathrm{a}}, z}$ of the air temperature gradient as it is always higher than $r_{e_{\mathrm{a}}, z}$ (as the uncertainty in $e_{\mathrm{a}}$ is higher due to the propagation of errors in $T_{\mathrm{a}}$ and $T_{\mathrm{w}}$ ). The second flag is for the case where the Bowen ratio approaches -1 , which causes the uncertainty in the BREB fluxes to be very high, as the denominator of Eqs. (12) and (13) approaches 0 (Payero et al., 2003):

Flag $1: r_{e_{\mathrm{a}}, z}^{2}>0.20$,

Flag $2: \beta<-1.1$ or $\beta>-0.9$.

If flag 1 is true, the outcome of the Bowen ratio calculation is considered reliable. The other data points are removed from further analysis. If flag 2 is also true, then the Bowen ratio can be used for calculating the atmospheric heat fluxes.

After processing the EC data using LI-COR's EddyPro ${ }^{\circledR}$ software (LI-COR Inc., 2016), several quality flags are available. The quality flag system used is from Mauder and Foken (2006), ranging from 0 (best) to 2 (worst). The EC fluxes with a quality flag of 0 or 1 are used in this research.

To summarize, the method of this paper differs in a few points from Euser et al. (2014). The fit of the Bowen ratio temperature and vapour pressure profiles is done separately, to get the correct ratio, as $\frac{\partial T}{\partial z} / \frac{\partial e_{\mathrm{a}}}{\partial z} \neq \frac{\partial T}{\partial e_{\mathrm{a}}}$. More energy balance storage terms are taken into account, namely the latent and specific heat storage in the air column. The potential temperature is used instead of the air temperature, to correct for the lapse rate. The local air pressure is taken into account in the calculations, as it has an influence on the psychrometric constant, specific heat capacity and specific humidity. Lastly, a system for simple quality flags is introduced to allow for simple objective quality control.

\section{Results and discussion}

\subsection{Meteorological conditions}

For the comparison of the DTS temperature with the reference temperature data (Sect. 4.2), the days 10-22 August 2016 are used.

For a good comparison between DTS and EC, both devices should work properly. Due to several technical problems with data collection, only 11 days within the measurement campaign have both EC and DTS data available, namely 10, 12 14, 19-22, and 28-30 August 2016. On the other days data are missing in either the EC or the DTS. The meteorological conditions of these days are shown in Fig. 4. All days were partially clouded, or completely clouded. The wind direction was mainly west and northeast. Above the canopy the wind speed varied between 2 and $6 \mathrm{~m} \mathrm{~s}^{-1}$, while under the canopy the wind speed was often too low to be measured with the cup anemometer (under $0.4 \mathrm{~m} \mathrm{~s}^{-1}$ ).

\subsection{Temperature validation}

In Fig. 5 the comparison between the $6 \mathrm{~mm}$ DTS cable and the reference sensor is shown. For the above-canopy comparison, the $46 \mathrm{~m}$ reference sensor is compared to the cable temperatures at $44 \mathrm{~m}$ height, as the temperatures at the top are unreliable due to influence from the sun and the warm water from the reservoir. Below the canopy the dry cable temperature correlates perfectly with the reference sensor temperature (Fig. 5e). In and above the canopy incoming solar radiation warms up the fibre optic cable (Fig. 5a, c), which causes an error at $34 \mathrm{~m}$, where no screen was installed. This error is a deviation of up to $3 \mathrm{~K}$ from the reference sensor temperature (for $1 \mathrm{~min}$ temperature averages). The comparison at $34 \mathrm{~m}$ also has an offset - this is a constant error of about $1 \mathrm{~K}$, due to the reference temperature sensor drift and inter-calibration problems. The addition of screens above the canopy largely reduces the error from solar radiation to under $1 \mathrm{~K}$, leading to a very good agreement between the two sensor types (Fig. 5a).

Below the canopy the wet cable temperature is in good agreement with the reference wet-bulb temperature (Fig. 5f), even though wind speeds were often low. This shows that the wet cable gives a good estimate of the wet-bulb temperature. At $34 \mathrm{~m}$, where no screens were placed, the error in the wet-bulb temperature is larger than the error in the air temperature. Deviations of up to $4 \mathrm{~K}$ occur in the measurement period. The shielded top part of the wet cable performs much better (Fig. 5b), and errors are small (under $1 \mathrm{~K}$ ).

\subsection{Bowen ratio verification}

The Bowen ratio resulting from the BR-DTS method ( $\left.\beta_{\text {DTS }}\right)$ is compared to the EC Bowen ratio $\left(\beta_{\mathrm{EC}}\right)$, at a 15 min averaging interval. In Fig. 6 the correlation between the EC Bowen ratio estimate and the BR-DTS is shown. It shows a grouping 

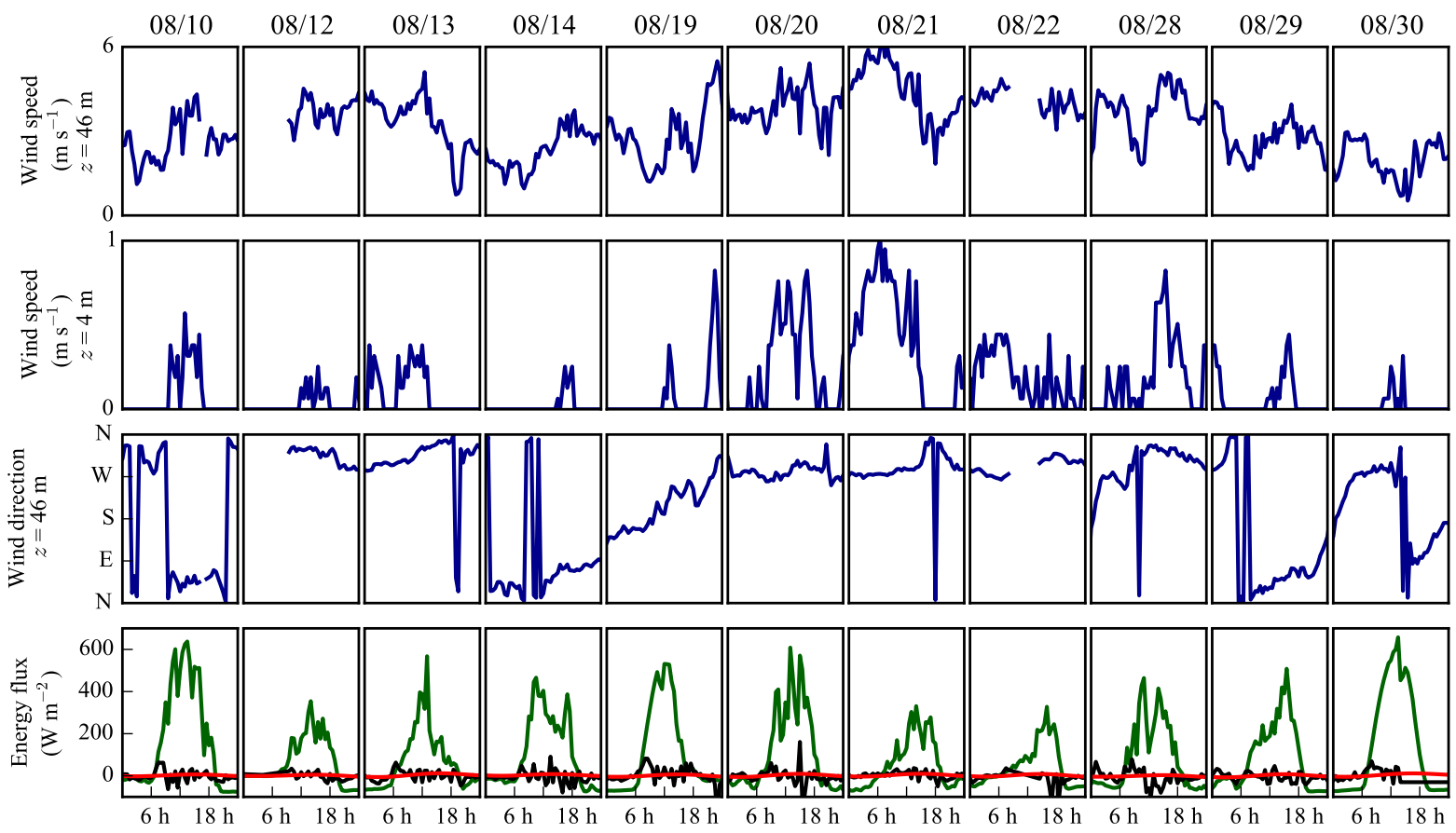

Figure 4. Meteorological conditions during the days that both DTS and EC data were available. From top to bottom: wind speed at the top of the tower, wind speed at the bottom of the tower, wind direction at the top of the tower, and the measured energy fluxes (green: net radiation; red: soil heat flux; black: energy storage change $\frac{\mathrm{d} Q}{\mathrm{~d} t}$ ).

around the $1: 1$ line, and a good correlation $\left(r^{2}=0.59\right)$. The EC Bowen ratio was only calculated for fluxes with an absolute value larger than $10 \mathrm{~W} \mathrm{~m}^{-2}$, as the uncertainty of the EC Bowen ratio is very high when the fluxes are small. Even the negative (night-time) values seemed to be accurate, since they passed the quality control flags. However, both EC and BR-DTS have problems measuring the night-time Bowen ratio. For EC this is due to the lower friction velocity at night (Wilson, 2002), while for the BR-DTS method the gradients are very small due to the small fluxes.

One drawback of the DTS-based Bowen ratio is the assumption that the eddy diffusivity of heat and water vapour are the same. In reality these eddy diffusivities can be dissimilar (Irmak et al., 2014). This can cause an error (both a bias and extra noise) in the Bowen ratio as measured by the temperature and vapour pressure gradients compared to the EC Bowen ratio. Another source of differences between $\beta_{\text {DTS }}$ and $\beta_{\mathrm{EC}}$ is that the two are measured at different heights.

During the measurement period the $80 \%$ fetch of the EC system was between 200 and $300 \mathrm{~m}$. By applying the findings of Stannard (1997), the Bowen ratio 80\% equilibrium ratio would be reached at a fetch-to-height ratio of 20 to 40 . This corresponds to a distance of 350 to $700 \mathrm{~m}$. The fetch of the Bowen ratio will therefore not be equal to the EC fetch, which could cause some differences in measured fluxes.

\subsection{Energy balance closure}

A known problem in measuring fluxes is that the energy balance often does not close well. This is caused by differences in fetch between the used devices, device inaccuracies, and possibly problems with the EC method (Wilson, 2002). Part of the difference between the BR-DTS method and the EC method may be explained by this energy balance closure problem. EC measurements have a fetch which does not include the area close to the flux tower. The available energy in the BR-DTS method depends on measurements of net radiation, ground heat flux and heat storage change $\left(\frac{\mathrm{d} Q}{\mathrm{~d} t}\right)$ close to the tower. Heterogeneity in the fetch may cause differences between the two methods. In addition, the biomass heat storage change $\left(\frac{\mathrm{d} Q_{\mathrm{B}}}{\mathrm{d} t}\right)$ was not measured for the BR-DTS method, and was assumed to be $0 \mathrm{~W} \mathrm{~m}^{-2}$. The photosynthesis energy flux $\left(G_{\mathrm{P}}\right)$ was also assumed to be $0 \mathrm{~W} \mathrm{~m}^{-2}$.

To investigate the energy balance closure for the two methods, we summed up the available fluxes in the following equations, where $\frac{\mathrm{d} Q}{\mathrm{~d} t}$ is the storage term from Eq. (14):

$$
\begin{aligned}
& B_{\mathrm{DTS}}=R_{\mathrm{N}}-G_{\mathrm{S}}-\frac{\mathrm{d} Q}{\mathrm{~d} t}, \\
& B_{\mathrm{EC}}=H_{\mathrm{EC}}+\rho \lambda E_{\mathrm{EC}},
\end{aligned}
$$

where $B_{\text {DTS }}$ is the energy available for heat fluxes in the BR-DTS method $\left(\mathrm{W} \mathrm{m}^{-2}\right)$ and $B_{\mathrm{EC}}$ is the sum of the ECmeasured heat fluxes $\left(\mathrm{W} \mathrm{m}^{-2}\right)$. 

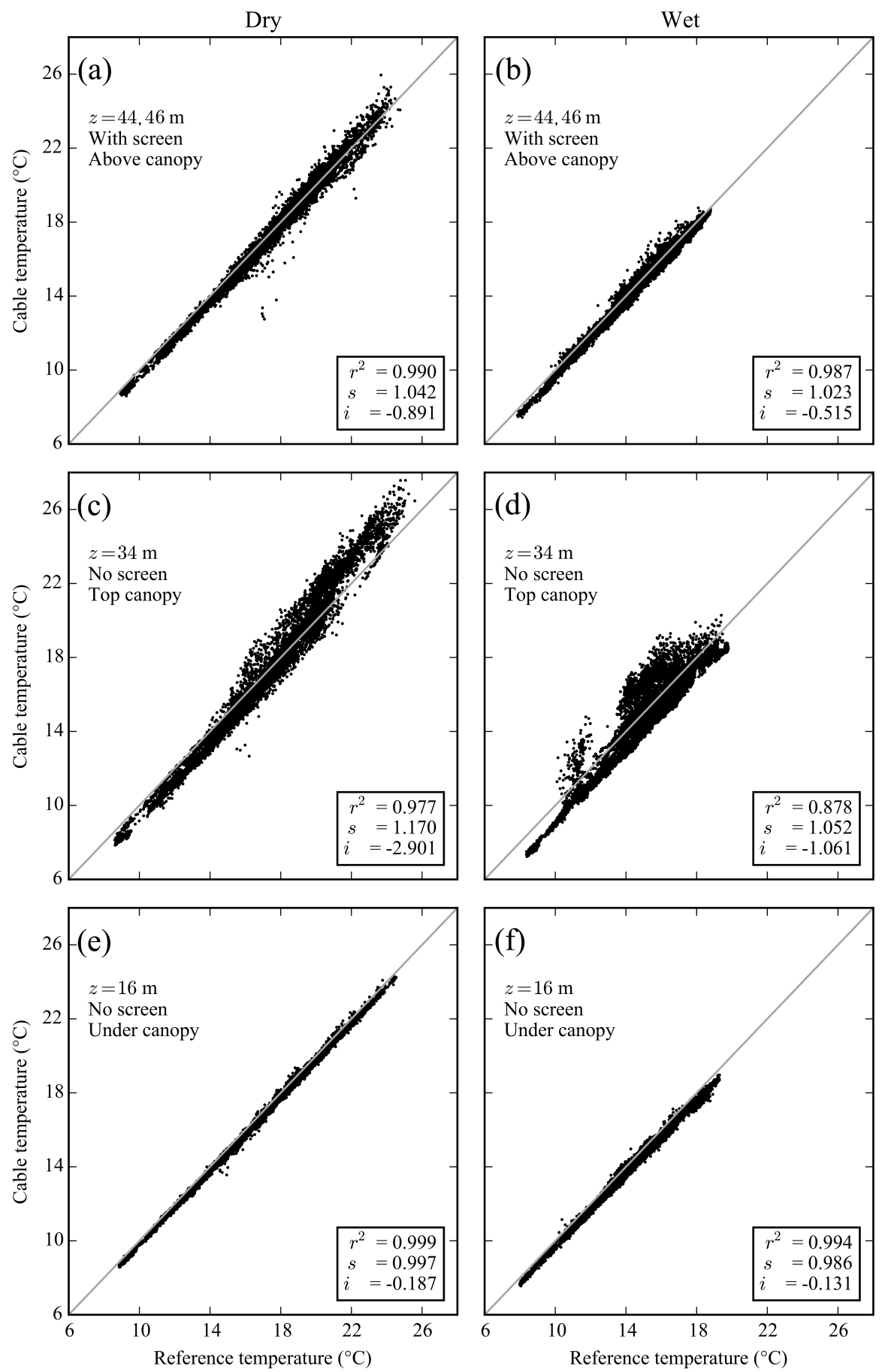

Figure 5. Comparison between the $6 \mathrm{~mm}$ DTS cable and reference temperatures. Grey line shows 1:1 correlation. Data from 10-23 August 2016. (a) Dry cable at $44 \mathrm{~m}$ and reference air temperature at $46 \mathrm{~m}$; the cable is shielded by the screen. (b) Wet cable at $44 \mathrm{~m}$ and reference wet-bulb temperature at $46 \mathrm{~m}$; the cable is shielded by the screen. (c) Dry cable and reference air temperature at $34 \mathrm{~m}$; the cable is exposed to direct sunlight. (d) Wet cable and reference wet-bulb temperature at $34 \mathrm{~m}$; the fibre optic cable is exposed to direct sunlight. (e) Dry cable and reference air temperature at $16 \mathrm{~m}$, under the canopy so less direct sunlight hits the fibre optic cable. (f) Wet cable and reference wet-bulb temperature at $16 \mathrm{~m}$, under the canopy so less direct sunlight hits the fibre optic cable. Shown are the linear correlation coefficients: the coefficient of determination $\left(r^{2}\right)$, the slope $(s)$ and the intercept $(i)$. 


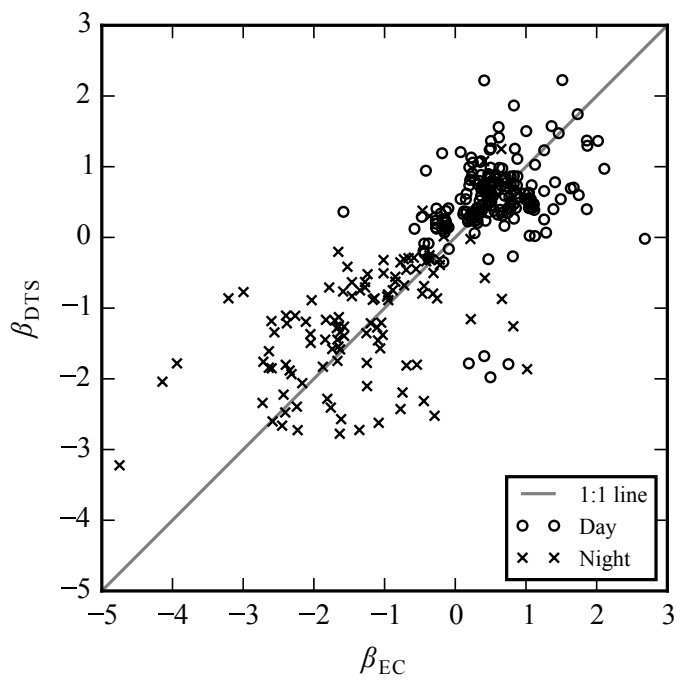

Figure 6. Correlation between the DTS-measured ( $\left.\beta_{\text {DTS }}\right)$ and ECmeasured $\left(\beta_{\mathrm{EC}}\right)$ Bowen ratios. Daytime data are between 07:00 and 18:00. Data from 10, 12-14, 19-22, and 28-30 August. $R^{2}=0.59$. $\mathrm{RMSE}=0.81 . n=319$ data points

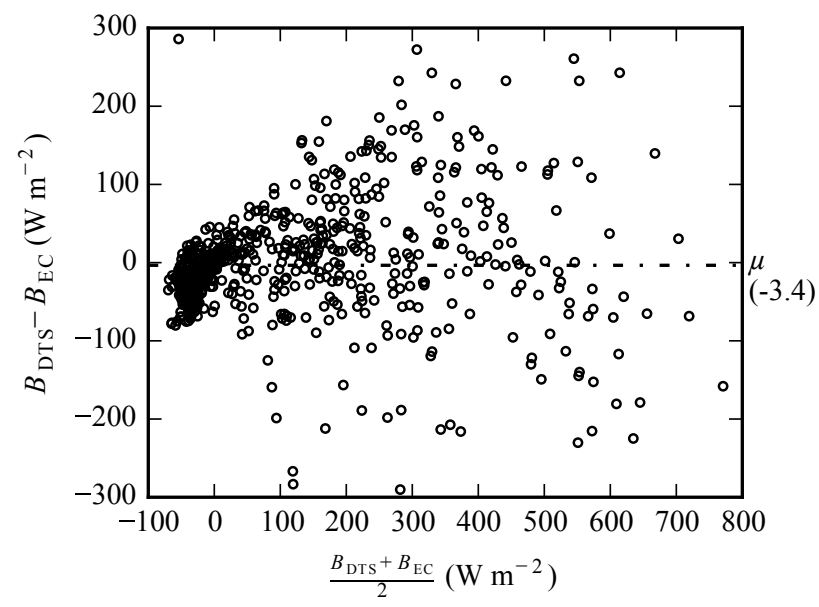

Figure 7. Tukey mean-difference plot comparing $B_{\mathrm{DTS}}$ and $B_{\mathrm{EC}}$. With $\mu=-3.4 \mathrm{~W} \mathrm{~m}^{-2}$, RMSE $=76 \mathrm{~W} \mathrm{~m}^{-2}, n=741$ data points (15 min averages). Data from 10, 12-14, 19-22, and 28-30 August 2016.

To compare the two measurement methods, a Tukey meandifference (or Bland-Altman) plot was made (Fig. 7) (Altman and Bland, 1983). The mean of the two measurement methods is plotted against the difference between them. The mean difference $(\mu)$ between $B_{\mathrm{DTS}}$ and $B_{\mathrm{EC}}$ is a $3.4 \mathrm{~W} \mathrm{~m}^{-2}$ underestimation by the BR-DTS method. At low fluxes (below $100 \mathrm{~W} \mathrm{~m}^{-2}$ ), the BR-DTS method measures less energy available for fluxes compared to EC. At high fluxes (over $400 \mathrm{~W} \mathrm{~m}^{-2}$ ) the opposite is visible. One possible reason for this is that the biomass heat flux $\left(\frac{\mathrm{d} Q_{\mathrm{B}}}{\mathrm{d} t}\right)$ was not measured,

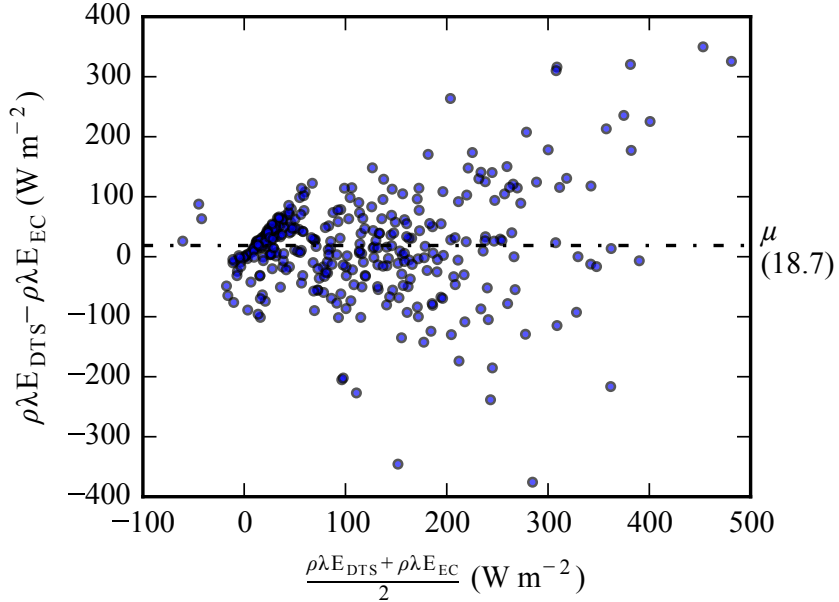

Figure 8. Tukey mean-difference plot comparing $\rho \lambda E_{\mathrm{EC}}$ and $\rho \lambda E_{\mathrm{DTS}}$. With $\mu=18.7 \mathrm{~W} \mathrm{~m}^{-2}$, RMSE $=90 \mathrm{~W} \mathrm{~m}^{-2}(15 \mathrm{~min} \mathrm{av}-$ erages). Data from 10, 12-14, 19-22, and 28-30 August 2016.

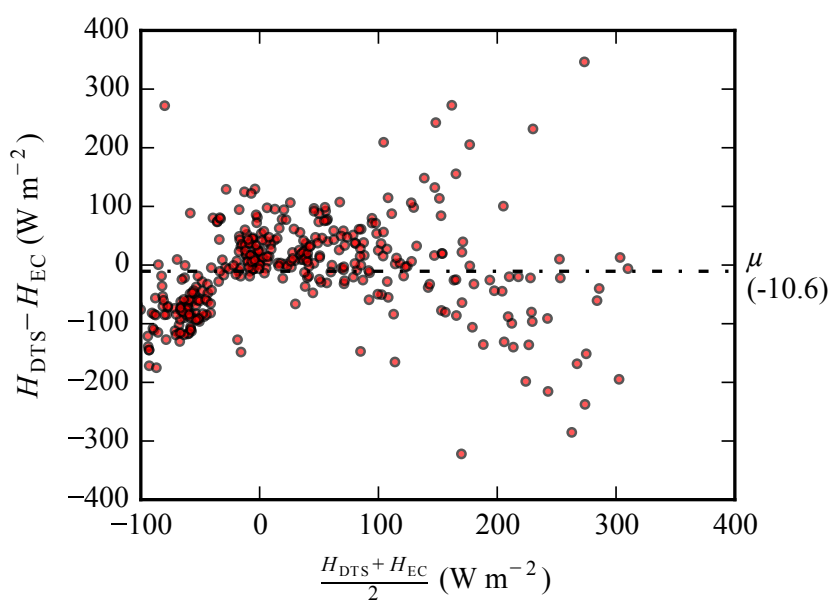

Figure 9. Tukey mean-difference plot comparing $H_{\mathrm{EC}}$ and $H_{\mathrm{DTS}}$ With $\mu=-10.6 \mathrm{~W} \mathrm{~m}^{-2}$, RMSE $=82 \mathrm{~W} \mathrm{~m}^{-2}$. (15 min averages). Data from 10, 12-14, 19-22, and 28-30 August 2016.

which causes an underestimation of the available energy in $B_{\mathrm{DTS}}$ during the night, and an overestimation during the day.

\subsection{Energy fluxes}

Figures 8 and 9 show the mean difference plots comparing the latent and sensible heat fluxes of the EC method to the BR-DTS method. The BR-DTS fluxes are calculated above the canopy, using only temperature data from the shielded cables. The Tukey mean-difference plot for the latent heat flux shows no large bias when comparing the BR-DTS method to EC, with the mean difference being a $18.7 \mathrm{~W} \mathrm{~m}^{-2}$ overestimation by the BR-DTS method (Fig. 8).

The Tukey mean-difference plot comparing the sensible heat flux (Fig. 9) shows a strong negative bias for negative 


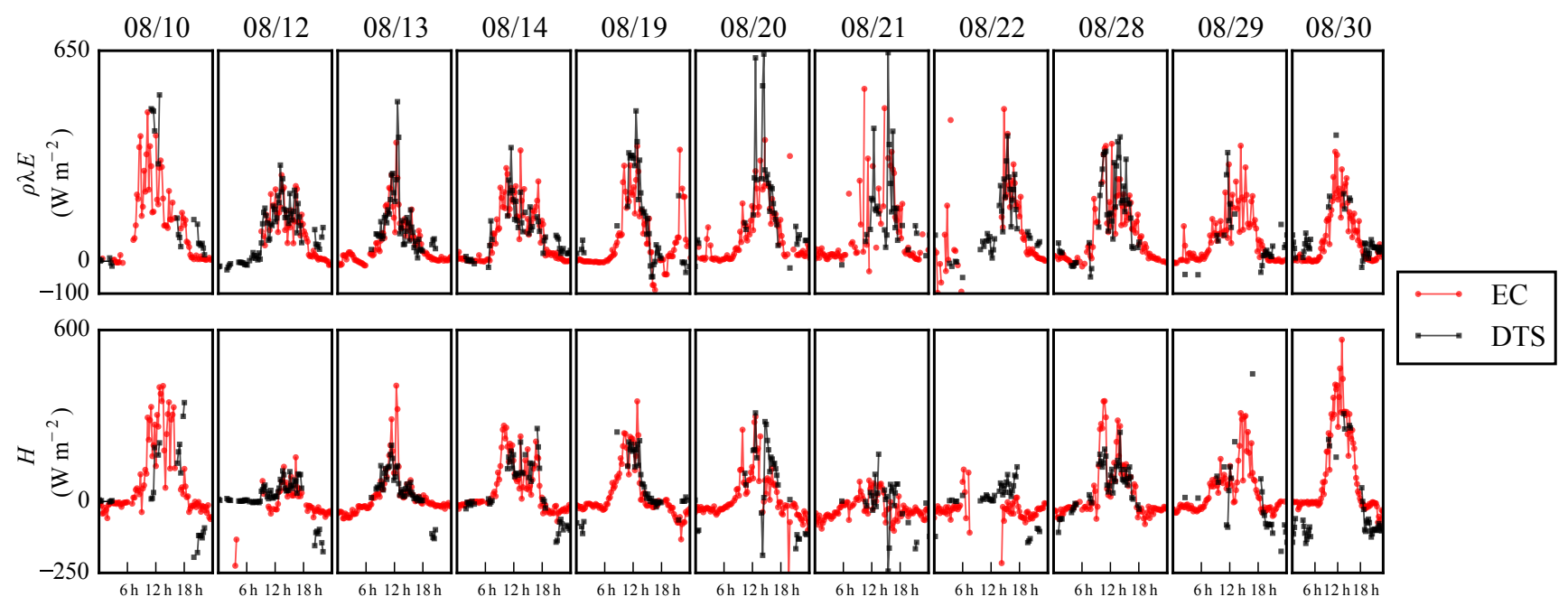

Figure 10. Plot comparing the BR-DTS and EC measured sensible $(H)$ and latent $(\rho \lambda E)$ heat fluxes over time (15 min averages). Data from 10, 12-14, 19-22, and 28-30 August 2016.

fluxes, resulting from the negative bias in the energy balance comparison (Fig. 7). At positive fluxes there seems to be a positive bias $\left(H_{\mathrm{DTS}}>H_{\mathrm{EC}}\right)$. The mean difference is small, being a $10.6 \mathrm{~W} \mathrm{~m}^{-2}$ underestimation by the BR-DTS method.

Figure 10 shows the time series of the BR-DTS and EC measured heat fluxes. The daytime flux estimates correspond well, and follow the same trends. The night-time BR-DTS estimates of the sensible heat flux are more negative than the EC estimates, one possible reason being the energy balance differences discussed before. On many days, during the early morning and start of the evening, the BR-DTS has missing values, which is mainly due to the inversion of the gradient, as the temperature gradients changes from negative (stable conditions) to positive (unstable conditions) and vice versa. This inversion causes uncertainty, which is filtered out by the quality control flags.

\section{Conclusions and recommendations}

This technical note investigates the use of the BR-DTS method above a forest canopy, and introduces a number of improvements on the method as presented by Euser et al. (2014). The performance is investigated by comparing the measured DTS cable temperatures to reference sensors, looking at energy balance closure, and comparing the measured Bowen ratio, sensible heat flux and latent heat flux to EC measurements.

When comparing the fibre optic cable temperature to reference sensors, it can be seen that the wet-bulb and air temperatures can be well represented. Under the canopy, where the cables are shaded from direct sunlight, the DTS cable and reference sensors are in near-perfect agreement. However, above the canopy direct sunlight may cause a large er- ror, up to $3 \mathrm{~K}$. This error can be largely mitigated by placing screens to block the sunlight, reducing the error to less than $1 \mathrm{~K}$. Hence screens are effective and should also be placed in the canopy.

The Bowen ratio measured by DTS correlates well with EC estimates $\left(r^{2}=0.59\right)$. A simple quality control method, using the goodness of fit of the vapour pressure gradient, also works well, and filters out most outliers and errors. The small gradients above the forest canopy are hard to measure accurately, which increases the uncertainty during days where fluxes (and thus gradients) are small. The Bowen ratio assumption that the eddy diffusivities of heat and vapour are equal was not studied, but can be a source of differences between the BR-DTS and EC methods. The difference in fetch for the two methods can also be a cause for differences.

The energy balance closure between the BR-DTS method and EC is in good agreement, with the mean difference being a $3.4 \mathrm{~W} \mathrm{~m}^{-2}$ underestimation by the BR-DTS method, and an uncertainty of RMSE $=76 \mathrm{~W} \mathrm{~m}^{-2}$. However, the BRDTS method estimates a more negative amount of available energy during night-time, and a more positive amount during daytime compared to EC. One cause could be the lack of biomass heat storage change measurements, which is of the order of $45 \mathrm{~W} \mathrm{~m}^{-2}$. Another source for the difference is that the energy balance components of the BR-DTS method are generally point measurements, while EC and the Bowen ratio both have a large fetch. As a result, heterogeneity can cause large differences in the available energy for latent and sensible heat fluxes.

When comparing the latent heat flux of the two methods, they are in agreement, although the uncertainty is high $\left(\right.$ RMSE $\left.=90 \mathrm{~W} \mathrm{~m}^{-2}\right)$. The BR-DTS method slightly overestimates the latent heat flux, with a mean difference of $18.7 \mathrm{~W} \mathrm{~m}^{-2}$. The results for the sensible heat flux are sim- 
ilar, with an uncertainty of RMSE $=82 \mathrm{~W} \mathrm{~m}^{-2}$, and the BR-DTS method underestimating the sensible heat flux by $10.6 \mathrm{~W} \mathrm{~m}^{-2}$. However, the underestimation mainly takes place during night-time, which can be caused by differences in available energy.

While the average profiles can be useful and valuable, extra information could be gained by opting for a smaller diameter fibre optic cable, and measuring at a high frequency $(1 \mathrm{~Hz})$. This could give new insights into surface interactions and could show convective cells transporting heat upwards.

A way to improve the performance of the BR-DTS method is to find an independent estimate for the sensible heat flux $(H)$, to avoid the uncertainties in the energy balance components $\left(R_{\mathrm{N}}, \frac{\mathrm{d} Q}{\mathrm{~d} t}\right)$. Through the universal functions of the Monin-Obukhov similarity theory estimates of the sensible heat flux can be made. This could be done either by measuring the wind speed over height (Stricker and Brutsaert, 1978) using DTS (Sayde et al., 2015) or by applying the flux-variance method (Katul et al., 1995). The Bowen ratio can then be used to calculate the latent heat flux.

Data availability. The data used in this study are available online from the 4TU data repository (https://doi.org/10.4121/uuid:5c81f10a-1249-4b85-8dec-

2b029dd88b99; Schilperoort et al., 2017).

Competing interests. The authors declare that they have no conflict of interest.

Acknowledgements. This research was funded by NWO Earth and Life Sciences (ALW), veni-project 863.15.022, the Netherlands. We would like to thank Murat Ucer and Christiaan van der Tol (University of Twente) for providing us with access to their measurement location and reference data, and the students Tara van Iersel and Tom Oostdijk for assisting with setting up the DTS measurements.

Edited by: Pierre Gentine

Reviewed by: two anonymous referees

\section{References}

Allen, R. G., Pereira, L. S., Raes, D., and Smith, M.: FAO Irrig. Drain. Paper No. 56, Irrig. Drain., 300, 300 pp., http://www. kimberly.uidaho.edu/water/fao56/fao56.pdf, 1998.

Altman, D. G. and Bland, J. M.: Measurement in Medicine: The Analysis of Method Comparison Studies, J. R. Stat. Soc. D-Sta., 32, 307-317, https://doi.org/10.2307/2987937, 1983.

Angus, D. E. and Watts, P. J.: Evapotranspiration - How good is the Bowen ratio method?, Agr. Water Manage., 8, 133-150, https://doi.org/10.1016/0378-3774(84)90050-7, 1984.
Bao, X. and Chen, L.: Recent progress in distributed fiber optic sensors, Sensors (Basel), 12, 8601-8639, https://doi.org/10.3390/s120708601, 2012.

Barr, A. G., King, K. M., Gillespie, T. J., Den Hartog, G., and Neumann, H. H.: A comparison of bowen ratio and eddy correlation sensible and latent heat flux measurements above deciduous forest, Bound.-Lay. Meteorol., 71, 21-41, https://doi.org/10.1007/BF00709218, 1994.

Bense, V., Read, T., and Verhoef, A.: Using distributed temperature sensing to monitor field scale dynamics of ground surface temperature and related substrate heat flux, Agr. Forest Meteorol., 220, 207-215, https://doi.org/10.1016/j.agrformet.2016.01.138, 2016.

Blume, T., Krause, S., Meinikmann, K., and Lewandowski, J.: Upscaling lacustrine groundwater discharge rates by fiber-optic distributed temperature sensing, Water Resour. Res., 49, 79297944, https://doi.org/10.1002/2012WR013215, 2013.

Bosveld, F. and Bouten, W.: Evaluation of transpiration models with observations over a Douglas-fir forest, Agr. Forest Meteorol., 108, 247-264, https://doi.org/10.1016/S0168-1923(01)00251-9, 2001.

Bowen, I. S.: The ratio of heat losses by conduction and by evaporation from any water surface, Phys. Rev., 27, 779-787, https://doi.org/10.1103/PhysRev.27.779, 1926.

de Jong, S. A. P., Slingerland, J. D., and van de Giesen, N. C.: Fiber optic distributed temperature sensing for the determination of air temperature, Atmos. Meas. Tech., 8, 335-339, https://doi.org/10.5194/amt-8-335-2015, 2015.

Erisman, J., Draaijers, G., Steingröver, E., Van Dijk, H., Boxman, A., and De Vries, W.: Assessment of the exposure and loads of acidifying and eutrophying pollutants and ozone, as well as their harmful influence on the vitality of the trees and the Speulder forest ecosystem as a whole, Water Air Soil Poll., 105, 539-571, 1998.

Euser, T., Luxemburg, W. M. J., Everson, C. S., Mengistu, M. G., Clulow, A. D., and Bastiaanssen, W. G. M.: A new method to measure Bowen ratios using high-resolution vertical dry and wet bulb temperature profiles, Hydrol. Earth Syst. Sci., 18, 20212032, https://doi.org/10.5194/hess-18-2021-2014, 2014.

Fuchs, M. and Tanner, C.: Error analysis of bowen ratios measured by differential psychrometry, Agr. Meteorol., 7, 329-334, https://doi.org/10.1016/0002-1571(70)90027-0, 1970.

Harrison, R. G. and Wood, C. R.: Ventilation effects on humidity measurements in thermometer screens, Q. J. Roy. Meteor. Soc., 138, 1114-1120, https://doi.org/10.1002/qj.985, 2012.

Irmak, S., Kilic, A., and Chatterjee, S.: On the Equality Assumption of Latent and Sensible Heat Energy Transfer Coefficients of the Bowen Ratio Theory for Evapotranspiration Estimations: Another Look at the Potential Causes of Inequalities, Climate, 2, 181-205, https://doi.org/10.3390/cli2030181, 2014.

Jansen, J., Stive, P. M., van de Giesen, N., Tyler, S., SteeleDunne, S. C., and Williamson, L.: Estimating soil heat flux using Distributed Temperature Sensing, GRACE, Remote Sensing and Ground-based Methods in Multi-Scale Hydrology, 140-144, 2011.

Katul, G., Goltz, S. M., Hsieh, C. I., Cheng, Y., Mowry, F., and Sigmon, J.: Estimation of surface heat and momentum fluxes using the flux-variance method above uniform 
and non-uniform terrain, Bound.-Lay. Meteorol., 74, 237-260, https://doi.org/10.1007/BF00712120, 1995.

Koutsoyiannis, D.: Clausius-Clapeyron equation and saturation vapour pressure: simple theory reconciled with practice, Eur. J. Phys., 33, 295-305, https://doi.org/10.1088/01430807/33/2/295, 2012.

LI-COR Inc.: EddyPro® Version 6.2 [Computer Software], 2016.

Mauder, M. and Foken, T.: Impact of post-field data processing on eddy covariance flux estimates and energy balance closure, Meteorol. Z., 15, 597-609, https://doi.org/10.1127/09412948/2006/0167, 2006.

Michiles, A. A. and Gielow, R.: Above-ground thermal energy storage rates, trunk heat fluxes and surface energy balance in a central Amazonian rainforest, Agr. Forest Meteorol., 148, 917-930, https://doi.org/10.1016/j.agrformet.2008.01.001, 2008.

Oliphant, A. J., Grimmond, C. S. B., Zutter, H. N., Schmid, H. P., Su, H. B., Scott, S. L., Offerle, B., Randolph, J. C., and Ehman, J.: Heat storage and energy balance fluxes for a temperate deciduous forest, Agr. Forest Meteorol., 126, 185-201, https://doi.org/10.1016/j.agrformet.2004.07.003, 2004.

Pal Arya, S.: Introduction to Micrometeorology, Academic Press, San Diego, California, 1988.

Payero, J. O., Neale, C. M. U., Wright, J. L., and Allen, R. G.: Guidelines for validating Bowen ratio data, T. ASAE, 46, 1051, https://doi.org/10.13031/2013.13967, 2003.

Raj, R., Hamm, N. A., van der Tol, C., and Stein, A.: Variance-based sensitivity analysis of BIOME-BGC for gross and net primary production, Ecol. Model., 292, 26-36, 2014.

Sayde, C., Thomas, C. K., Wagner, J., and Selker, J.: High-resolution wind speed measurements using actively heated fiber optics, Geophys. Res. Lett., 42, 10064-10073, https://doi.org/10.1002/2015GL066729, 2015.

Schilperoort, B., Cisneros Vaca, C. R., and Jiménez Rodríguez, C. D.: Speulderbos flux, storage, and temperature profile measurements, https://doi.org/10.4121/uuid:5c81f10a-12494b85-8dec-2b029dd88b99, 2017.

Selker, J. S., Thévenaz, L., Huwald, H., Mallet, A., Luxemburg, W., Van De Giesen, N., Stejskal, M., Zeman, J., Westhoff, M., and Parlange, M. B.: Distributed fiber-optic temperature sensing for hydrologic systems, Water Resour. Res., 42, 1-8, https://doi.org/10.1029/2006WR005326, 2006.

Silixa Ltd: ULTIMA ${ }^{\circledR}$ DTS, available at: http://silixa.com/ technology/ultima-dts/, last access: 26 June 2017.

Sluijter, R.: De Bosatlas van het klimaat, Noordhoff Uitgevers, Groningen, 2011.

Stannard, D. I.: A Theoretically Based Determination of Bowenratio Fetch Requirements, Bound.-Lay. Meteorol., 83, 375-406, https://doi.org/10.1023/A:1000286829849, 1997.

Steele-Dunne, S. C., Rutten, M. M., Krzeminska, D. M., Hausner, M., Tyler, S. W., Selker, J., Bogaard, T. A., and Van De Giesen, N. C.: Feasibility of soil moisture estimation using passive distributed temperature sensing, Water Resour. Res., 46, 112, https://doi.org/10.1029/2009WR008272, 2010.

Stricker, H. and Brutsaert, W.: Actual evapotranspiration over a summer period in the "Hupsel catchment", J. Hydrol., 39, 139157, https://doi.org/10.1016/0022-1694(78)90119-1, 1978.
Stull, R.: Practical Meteorology - An Algebra-based Survey of Atmospheric Science, Department of Earth, Ocean \& Atmospheric Sciences, University of British Columbia, Vancouver, BC, https://doi.org/10.14288/1.0300441, 2015.

Su, Z., Timmermans, W. J., van der Tol, C., Dost, R., Bianchi, R., Gómez, J. A., House, A., Hajnsek, I., Menenti, M., Magliulo, V., Esposito, M., Haarbrink, R., Bosveld, F., Rothe, R., Baltink, H. K., Vekerdy, Z., Sobrino, J. A., Timmermans, J., van Laake, P., Salama, S., van der Kwast, H., Claassen, E., Stolk, A., Jia, L., Moors, E., Hartogensis, O., and Gillespie, A.: EAGLE 2006 Multi-purpose, multi-angle and multi-sensor in-situ and airborne campaigns over grassland and forest, Hydrol. Earth Syst. Sci., 13, 833-845, https://doi.org/10.5194/hess-13-833-2009, 2009.

Thomas, C. K., Kennedy, A. M., Selker, J. S., Moretti, A., Schroth, M. H., Smoot, A. R., Tufillaro, N. B., and Zeeman, M. J.: High-Resolution Fibre-Optic Temperature Sensing: A New Tool to Study the Two-Dimensional Structure of Atmospheric Surface-Layer Flow, Bound.-Lay. Meteorol., 142, 177192, https://doi.org/10.1007/s10546-011-9672-7, 2012.

Tietema, A., Mol-Dijkstra, J. P., Kros, J., and De Vries, W.: Dynamic nitrogen deposition thresholds during forest stand development in a Douglas fir forest analysed with two nitrogen models SMART2 and MERLIN, Hydrol. Earth Syst. Sci., 6, 375-382, https://doi.org/10.5194/hess-6-375-2002, 2002.

Tiktak, A. and Bouten, W.: Soil water dynamics and long-term water balances of a Douglas fir stand in the Netherlands, J. Hydrol., 156, 265-283, 1994.

van der Tol, C.: Validation of remote sensing of bare soil ground heat flux, Remote Sens. Environ., 121, 275-286, https://doi.org/10.1016/j.rse.2012.02.009, 2012.

Van Wijk, M., Dekker, S., Bouten, W., Bosveld, F., Kohsiek, W., Kramer, K., and Mohren, G.: Modeling daily gas exchange of a Douglas-fir forest: comparison of three stomatal conductance models with and without a soil water stress function, Tree Physiol., 20, 115-122, 2000.

Weligepolage, K., Gieske, A., and Su, Z.: Surface roughness analysis of a conifer forest canopy with airborne and terrestrial laser scanning techniques, Int. J. Appl. Earth Obs., 14, 192-203, https://doi.org/10.1016/j.jag.2011.08.014, 2012.

Weligepolage, K., Gieske, A., and Su, Z.: Effect of spatial resolution on estimating surface albedo: A case study in Speulderbos forest in The Netherlands, Int. J. Appl. Earth Obs., 23, 18-28, 2013.

Westhoff, M. C., Savenije, H. H. G., Luxemburg, W. M. J., Stelling, G. S., van de Giesen, N. C., Selker, J. S., Pfister, L., and Uhlenbrook, S.: A distributed stream temperature model using high resolution temperature observations, Hydrol. Earth Syst. Sci., 11, 1469-1480, https://doi.org/10.5194/hess-11-1469-2007, 2007.

Wilkes, P., Lau, A., Disney, M., Calders, K., Burt, A., de Tanago, J. G., Bartholomeus, H., Brede, B., and Herold, M.: Data acquisition considerations for Terrestrial Laser Scanning of forest plots, Remote Sens. Environ., 196, 140-153, https://doi.org/10.1016/j.rse.2017.04.030, 2017.

Wilson, K.: Energy balance closure at FLUXNET sites, Agr. Forest Meteorol., 113, 223-243, https://doi.org/10.1016/S01681923(02)00109-0, 2002. 